\title{
Boerhaave syndrome due to excessive alcohol consumption: two case reports
}

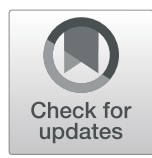

Yuichiro Haba ${ }^{1,2^{*}}$, Shungo Yano ${ }^{1}$, Hikaru Akizuki ${ }^{2}$, Takashi Hashimoto ${ }^{3}$, Toshio Naito ${ }^{1}$ and Naoyuki Hashiguchi ${ }^{2}$

\begin{abstract}
Background: Spontaneous esophageal rupture, or Boerhaave syndrome, is a fatal disorder caused by an elevated esophageal pressure owing to forceful vomiting. Patients with Boerhaave syndrome often present with chest pain, dyspnea, and shock. We report on two patients of Boerhaave syndrome with different severities that was triggered by excessive alcohol consumption and was diagnosed immediately in the emergency room.

Case presentation: The patient in case 1 complained of severe chest pain and nausea and vomited on arrival at the hospital. He was subsequently diagnosed with Boerhaave syndrome coupled with mediastinitis using computed tomography (CT) and esophagogram. An emergency operation was successfully performed, in which a $3-\mathrm{cm}$ tear was found on the left posterior wall of the distal esophagus. The patient subsequently had anastomotic leakage but was discharged 41 days later. The patient in case 2 complained of severe chest pain, nausea, vomiting, and hematemesis on arrival. He was suggested of having Boerhaave syndrome without mediastinitis on CT. The symptoms gradually disappeared after conservative treatment. Upper gastrointestinal endoscopy performed on the ninth day revealed a scar on the left wall of the distal esophagus. The patient was discharged 11 days later. In addition to the varying severity between the cases, the patient in case 2 was initially considered to have MalloryWeiss syndrome.

Conclusion: Owing to similar histories and symptoms, Boerhaave syndrome and Mallory-Weiss syndrome must be accurately distinguished by emergency clinicians. CT can be a useful modality to detect any severity of Boerhaave syndrome and also offers the possibility to distinguish Boerhaave syndrome from Mallory-Weiss syndrome.
\end{abstract}

Keywords: Boerhaave syndrome, Mallory-Weiss syndrome, Chest pain, Vomiting, Hematemesis

\section{Background}

Boerhaave syndrome was first reported by Hermann Boerhaave in 1724 as a case of esophageal rupture caused by vomiting after a large meal [1]. It is induced by increased esophageal pressure followed by straining, which can result from retching, vomiting, weightlifting, childbirth, or defecation [2]. It is generally difficult to promptly diagnose Boerhaave syndrome, and patients can have fatal

\footnotetext{
* Correspondence: yhaba@juntendo.ac.jp

'Department of General Medicine, Juntendo University School of Medicine, 2-1-1 Hongo, Bunkyo-ku, Tokyo 113-8421, Japan

${ }^{2}$ Department of Emergency and Disaster Medicine, Juntendo University School of Medicine, 2-1-1 Hongo, Bunkyo-ku, Tokyo 113-8421, Japan

Full list of author information is available at the end of the article
}

consequences if not intervened early [3]. It is also crucial to correctly distinguish Boerhaave syndrome from Mallory-Weiss syndrome as they share similar etiologies and initial clinical manifestations; however, they differ with respect to the site and depth of laceration, treatment administered, and prognosis. Commonly, patients with Boerhaave syndrome present with transmural lacerations to the left wall of the distal esophagus, requiring surgery for repair and reinforcement of ruptured wounds, irrigation, and drainage [3]. Conversely, patients with MalloryWeiss syndrome have lacerations to the submucosal layer of the gastric cardia, warranting good prognoses with endoscopic hemostases or conservative therapies.

(c) The Author(s). 2020 Open Access This article is licensed under a Creative Commons Attribution 4.0 International License, which permits use, sharing, adaptation, distribution and reproduction in any medium or format, as long as you give appropriate credit to the original author(s) and the source, provide a link to the Creative Commons licence, and indicate if changes were made. The images or other third party material in this article are included in the article's Creative Commons licence, unless indicated otherwise in a credit line to the material. If material is not included in the article's Creative Commons licence and your intended use is not permitted by statutory regulation or exceeds the permitted use, you will need to obtain permission directly from the copyright holder. To view a copy of this licence, visit http://creativecommons.org/licenses/by/4.0/ The Creative Commons Public Domain Dedication waiver (http://creativecommons.org/publicdomain/zero/1.0/) applies to the data made available in this article, unless otherwise stated in a credit line to the data. 


\section{Case presentation \\ Case 1}

A 45-year-old man with a history of hypertension, dyslipidemia, and habitual drinking visited our hospital with complaints of severe chest pain, back pain, bilateral shoulder pain, and vomiting. He fell ill after heavily consuming alcohol for a day. Three and a half hours prior to his arrival, he experienced discomfort in his chest followed by vomiting. Two hours and $20 \mathrm{~min}$ prior to his arrival, he felt nauseated, describing a feeling of sudden stiffness throughout his entire upper body. On arrival, he was alert, his blood pressure was 139/98 $\mathrm{mmHg}$, pulse rate was $64 / \mathrm{min}$ and regular, body temperature was $36.5^{\circ} \mathrm{C}$, respiratory rate was $20 / \mathrm{min}$, and oxygen saturation was $95 \%$. He was $173 \mathrm{~cm}$ tall and weighed 73.1 kg. No abnormalities other than cold sweat and epigastric tenderness were noted on physical examination. Chest radiography of the lateral view (seated position) showed several areas of free-air just below the diaphragm (Fig. 1). Contrast-enhanced computed tomography (CT) showed free-air, bilateral pleural effusion, and a dilated esophagus and stomach (Fig. 2). Based on these findings, an esophageal rupture with mediastinitis was the definitive conclusion and he was thus diagnosed with Boerhaave syndrome. A subsequent esophagogram further confirmed the diagnosis. Nine hours after the onset of the rupture, an emergency operation was performed as follows. Through a left thoracoabdominal incision, closure of the perforation and drainage of both the mediastinum and thoracic/abdominal cavities were

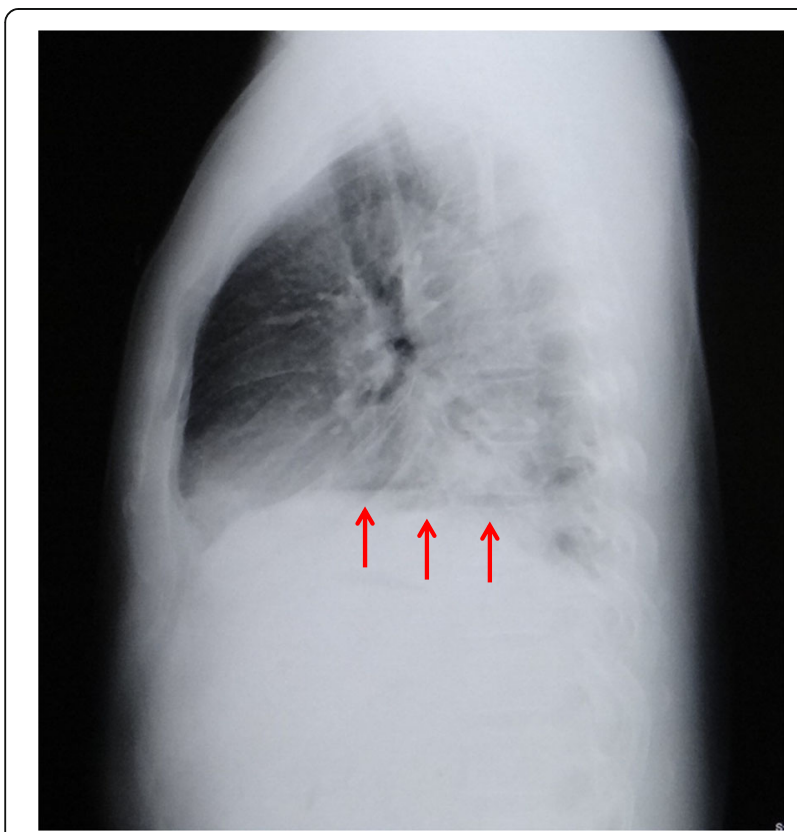

Fig. 1 Chest X-ray of the lateral view (seated position) on arrival in case 1. Several areas of free-air (arrows) just below the diaphragm are evident performed in succession. The penetrating laceration was approximately $3 \mathrm{~cm}$ in length vertically on the left posterior wall of the distal esophagus and was patched with the patient's omentum. Although the patient had a complication of anastomotic insufficiency on the 16th day, it was ultimately resolved. The patient was then administered a liquid diet on the 35th day, and he was discharged on the 41st day. Upper gastrointestinal endoscopy was performed on the 98th day, and a scar due to the suture was observed in the same location as the previous perforation (Fig. 3).

\section{Case 2}

A 27-year-old previously healthy man visited our hospital with complaints of vomiting, hematemesis, pyrosis, severe chest pain, and epigastralgia. He had been drinking alcohol heavily until $14 \mathrm{~h}$ prior to his arrival. Six hours prior to his arrival, he experienced epigastralgia and nausea, followed by retching and diarrhea. Three and a half hours prior to his arrival, he started experiencing pyrosis and intermittent chest pain and had an episode of hematemesis. On arrival, he was alert, his blood pressure was 110/ $62 \mathrm{mmHg}$, pulse rate was $96 / \mathrm{min}$ and regular, body temperature was $37.4{ }^{\circ} \mathrm{C}$, respiratory rate was $18 / \mathrm{min}$, and oxygen saturation was $97 \%$. He was $172.3 \mathrm{~cm}$ tall and weighed $53.5 \mathrm{~kg}$. Epigastric tenderness and retrosternal pain with forced respiration were noted on physical examination. Although chest radiography showed no findings, plain CT showed small areas of free-air in the mediastinum (Fig. 4). At first, Mallory-Weiss syndrome was suggested because of hematemesis, but CT suggested Boerhaave syndrome. No hematemesis recurred during his hospitalization, and his condition was followed up on via esophagogram and CT. Upper endoscopy was performed on the ninth day, and a linear scar was observed on the left wall of the distal esophagus, including at the esophagogastric junction (EGJ) (Fig. 5). The injury healed after conservative treatment that included rest, no oral consumption, and preventive antibiotics. He was discharged on the 11th day.

\section{Discussion and conclusions}

A comparison of the two cases is shown in Table 1. Both patients were equally distressed on arrival, but the clinical course was more complicated in case 1 than in case 2. The diagnoses of both cases were conventional and symptomatic, involving vomiting, pain in the lower thorax, and mediastinal emphysema [4].

Esophagography, upright chest radiography, and chest $\mathrm{CT}$ are useful for accurately diagnosing Boerhaave syndrome $[5,6]$. In cases similar to case 1 , in which patients present with major hydropneumothorax or pneumomediastinum, chest radiography is more appropriate. If such presentations are minor, as in case 2, CT is 

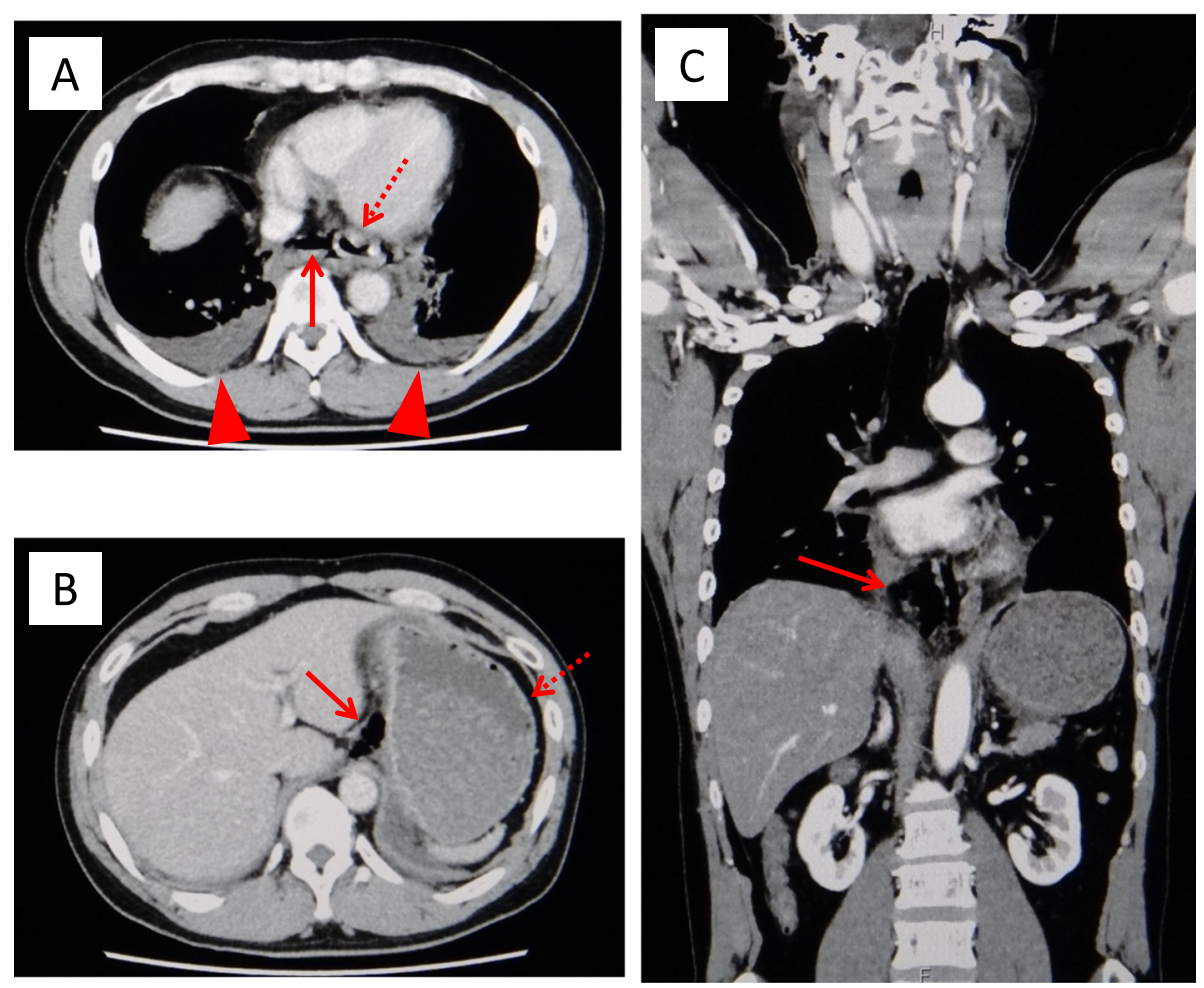

Fig. 2 Contrast-enhanced CT on arrival in case 1 ( $\mathbf{a}, \mathbf{b}$ transverse section; c sagittal section). Free-air (arrows) around the distal esophagus, the lesser curvature of the stomach, and the para-aortic area of the abdomen is observed. Bilateral pleural effusion (arrowheads), and the dilated esophagus and stomach (dotted-line arrows) are also observed

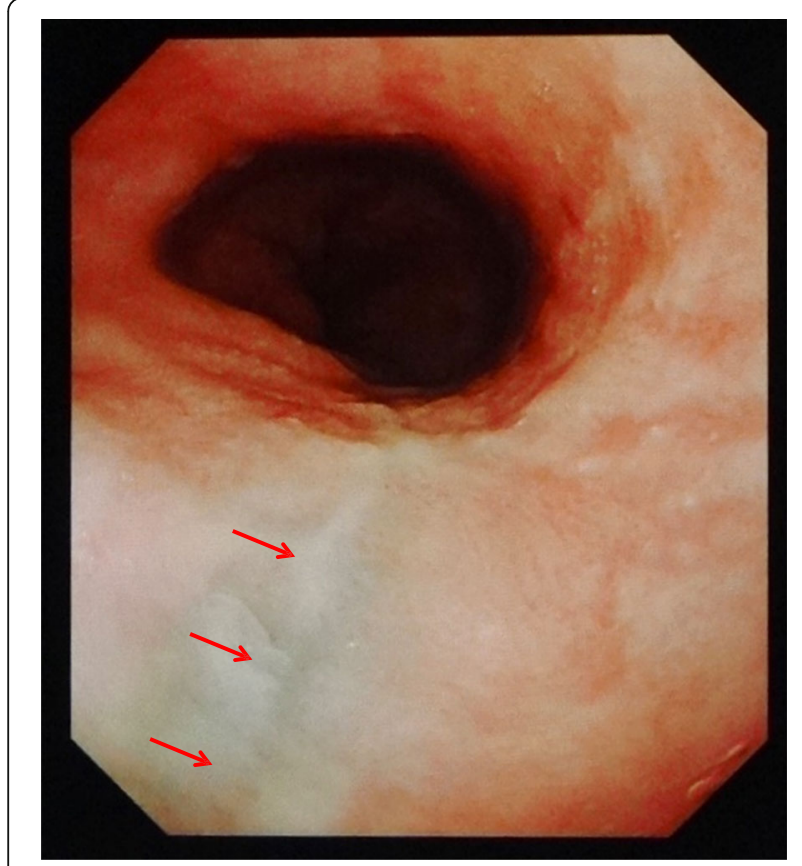

Fig. 3 Upper endoscopy performed 98 days after the first visit in case 1. A scar (arrows) after the suture is observed on the left posterior wall of the distal esophagus $38-41 \mathrm{~cm}$ from the incisors preferred, owing to recent improvements in imaging quality. In case 2, conservative treatment revealed that if inflammation due to the rupture is localized in the mediastinum, non-operative choices might be successful [3]. Radiological modalities, however, are not useful for the diagnosis of Mallory-Weiss syndrome. In cases where Boerhaave syndrome is unlikely, endoscopy is recommended for the diagnosis and concurrent treatment, as the source of bleeding in Mallory-Weiss syndrome is difficult to detect even with contrast-enhanced imaging studies.

Boerhaave syndrome occurs owing to the lack of coordination between the upper and lower esophageal sphincters, resulting in a transmural tear of the distal esophageal wall due to an increased intragastric pressure transmitted to the esophagus during vomiting [7]. In both presented cases, the left wall of the distal third of the esophagus was torn. This is a distinctly common localization due to the thin muscular layer, nerve and vascular entry points, and lack of support for the surrounding connective tissue [7].

Several reports have described diagnostic errors in which esophageal rupture was diagnosed as MalloryWeiss syndrome [8-10]. Commonly, massive hematemesis with less pain indicates Mallory-Weiss 


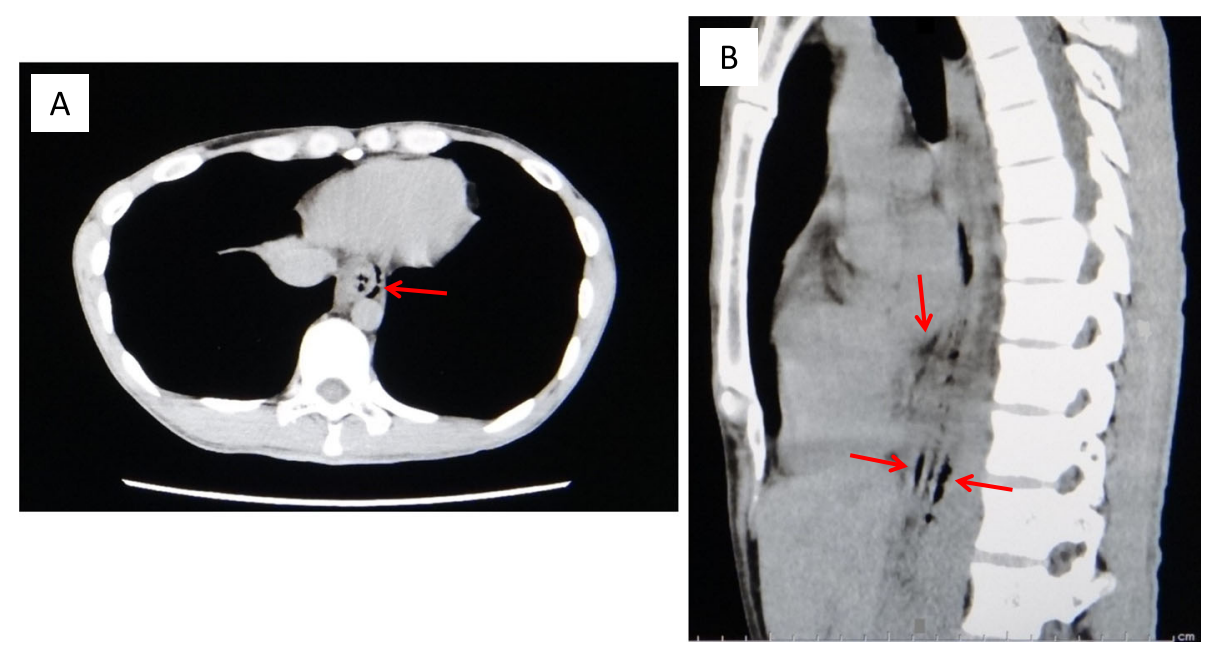

Fig. 4 Plain CT on arrival in case 2 (a transverse section; b sagittal section). Small free-air (arrows) is observed in the mediastinum around both the EGJ and the boundary between the middle and lower thoracic esophagus

syndrome, while minimal hematemesis with more pain indicates Boerhaave syndrome, despite both disorders presenting with an onset of vomiting after heavy drinking. Hematemesis was observed in case 2, but the endoscopic findings showed a scar only on the esophagus, not on the stomach; moreover, Mallory-Weiss lesions were not observed at all (Fig. 5).

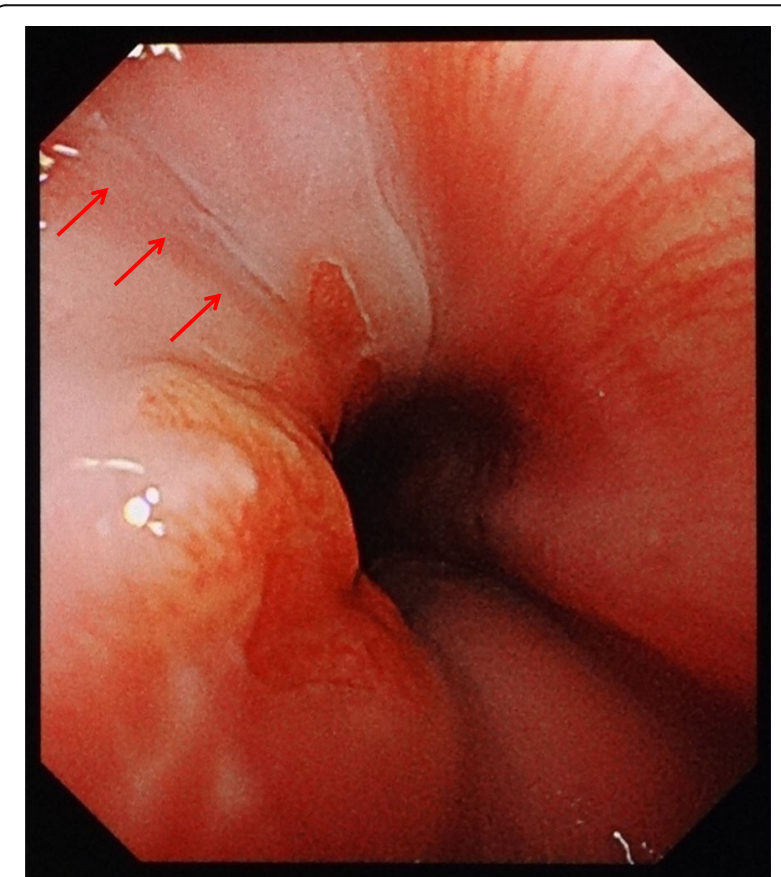

Fig. 5 Upper endoscopy performed 9 days after the first visit in case 2. A linear scar (arrows) is observed on the left wall of the distal esophagus, including the EGJ
The etiologies of both Boerhaave and MalloryWeiss syndromes are similar, both result from abnormally elevated intraluminal cardio-esophageal pressure during vomiting. Prior studies have mentioned the relationship between the two syndromes [11-17], with some even identifying Boerhaave syndrome as an extension of Mallory-Weiss syndrome [12-17]. However, this may be disputed for two reasons: the differences in the common sites (left distal esophagus vs. gastric cardia) and the scarcity of reported transitional cases. Our review of accessible transitional cases [14-17]-except for one case [17] that might have a true transitional lesion-showed that those cases [14-16] not only had several lacerations that extended into the submucosa of the gastric cardia but also a separate single laceration through all layers of the distal esophagus. Thus, the two syndromes are distinct, and it is worth considering that many transitional cases are situations in which both syndromes occurred independently in the same individual. Regarding pathophysiology, Mallory-Weiss lacerations are caused by repeated retching and primarily involve the part of the gastric cardia that includes the EGJ. Boerhaave's lacerations, on the other hand, may occur all at once in the weakest part of the esophageal wall, as the muscular layer initially tears before the mucosal layer when an explosive force is applied [18].

In summary, we report two cases of Boerhaave syndrome with different severities. Severity may vary greatly among patients with this disorder. Plain CT can quickly and easily detect any severity of the syndrome. Further, it can differentiate Boerhaave from Mallory-Weiss syndrome; thus, it is recommended as a preliminary test, if feasible. Although the initial cause of Boerhaave 
Table 1 Comparison of the reported cases

\begin{tabular}{lll}
\hline & Case $\mathbf{1}$ & Case $\mathbf{2}$ \\
\hline Age (years) & 45 & 27 \\
Physique (body mass index) & 24.4 & 18.0 \\
Symptoms & Vomiting, chest pain, back pain, bilateral shoulder & $\begin{array}{l}\text { Vomiting, chest pain, epigastralgia, hematemesis, } \\
\text { pyrosis }\end{array}$ \\
Severity & Distressed & Distressed \\
Trigger & Excessive drinking from the previous day & Excessive drinking from the previous day \\
Hematemesis & - & + \\
Operation & + & - \\
Location & On the left posterior wall of the distal esophagus & On the left wall of the distal esophagus \\
First endoscopy & Day 68 & Day 9 \\
Period of hospitalization & 41 days & 11 days \\
Estimated time from onset to rupture & $1.2 \mathrm{~h}$ & $2.5 \mathrm{~h}$ \\
Estimated time from rupture to operation & $9 \mathrm{~h}$ & (No operation) \\
room & &
\end{tabular}

syndrome is the same as that of Mallory-Weiss syndrome, the nature of the two syndromes is distinctive and correct diagnosis is essential for positive patient outcomes.

\section{Abbreviations}

CT: Computed tomography; EGJ: Esophagogastric junction

\section{Acknowledgements}

None

\section{Authors' contributions}

All authors have significantly contributed to the paper. $\mathrm{YH}$ contributed to the whole study conception and design, literature review, and manuscript writing and correction. SY, HA, TN, and NH contributed to patient management in the emergency room and checked the manuscript. $\mathrm{TH}$ contributed to the "Discussion and conclusions" section as an esophagus specialist. The authors read and approved the final manuscript.

\section{Funding}

No funding was required in preparation of the manuscript.

\section{Availability of data and materials}

Not applicable

\section{Ethics approval and consent to participate}

This report was prepared in accordance with the ethical standards of the institutional ethics committee and with the 1964 Helsinki Declaration.

\section{Consent for publication}

Written informed consent was obtained from all patients prior to publication of this report.

\section{Competing interests}

The authors declare that they have no competing interests. This manuscript has not been published and is not under consideration for publication elsewhere. Additionally, all of the authors have approved the contents of this paper and have agreed to the journal's submission policies.

\section{Author details}

'Department of General Medicine, Juntendo University School of Medicine, 2-1-1 Hongo, Bunkyo-ku, Tokyo 113-8421, Japan. ²Department of Emergency and Disaster Medicine, Juntendo University School of Medicine, 2-1-1 Hongo, Bunkyo-ku, Tokyo 113-8421, Japan. ${ }^{3}$ Department of Esophageal and
Gastroenterological Surgery, Juntendo University School of Medicine, Tokyo, Japan.

Received: 12 August 2020 Accepted: 16 November 2020

Published online: 30 November 2020

\section{References}

1. Boerhaave $\mathrm{H}$. Atrocis, nec descripti prius, morbid historia sccundum medicac artis leges conscripta, lugduni batavorum, boutesteniana. Medici. 1724; 60. Translated in Bull Med Libr Assos. 1955;43:217-40.

2. Turner AR, Turner SD. Boerhaave syndrome. StatPearls Publ. 2020. https:// www.ncbi.nlm.nih.gov/books/NBK430808/. Accessed 25 July 2020.

3. Schipper P, Gunne AFP, Oostvogel HJM, Laarhoven CJHM. Spontaneous rupture of the oesophagus: Boerhaave's syndrome in 2008. Literature review and treatment algorithm. Dig Surg. 2009;26:1-6.

4. Mackler SA. Spontaneous rupture of the esophagus. An experimental and clinical study. Surg Gynecol Obestet. 1952;95:345-56

5. Henderson JAM, Peloquin AJM. Boerhaave revisited: spontaneous esophageal perforation as a diagnostic masquerader. Am J Med. 1989;86: 559-67.

6. Jagminas L, Silverman RA. Boerhaave's syndrome presenting with abdominal pain and right hydropneumothorax. Am J Emerg Med. 1996:14: $53-6$.

7. Janssens J, Valembois P. Spontaneous rupture of the esophagus (Boerhaave's syndorome). Disease of the esophagus, Springer-Verlag, Berlin, Heidelberg, New York: 1974. p. 675-82.

8. Urimoto G, Kaneda T, Suzuki T. A case report: Spontaneous rupture of the esophagus that was diagnosed at thirteen days after the onset. Sosei (Jpn J Reanimatol). 2010:30:20-2

9. Mizutani K, Makuuchi H, Machimura T, Shimada H, Chino O, Nishi T, et al. Spontaneous esophageal rupture diagnosed Mallory-Weiss syndrome at the initial medical examination, report of a case. Itocho (Stomach and Intestine). 1997:32:1201-4.

10. Hansen CP, Bertelsen S. Boerhaave's syndrome: spontaneous rupture of the oesophagus. Ann Chir Gynaecol. 1988;77:138-41.

11. Small AB, Ellis PR. Laceration of the distal esophagus due to vomiting (the Mallory-Weiss syndrome): report of a case with massive hemorrhage and recovery after repair of the laceration. N Engl J Med. 1958;258:285-6.

12. Wessely JY, Lemee J, Breil P, Fekete F. Mallory-Weiss syndrome, Boerhaave syndrome. A possible association. Nouv Presse Med. 1981;10:175-6.

13. Zikria BA, Rosenthal AD, Potter RT, Ferrer JM Jr. Mallory-Weiss syndrome and emetogenic (spontaneous) rupture of the esophagus. Ann Surg. 1965;162: $151-5$.

14. Thopson NW, Calvin BE, William JF. The spectrum of emetogenic injury to the esophagus and stomach. Am J Surg. 1967;113:13-26. 
15. Kiyama T, Sasajima K, Hayashi H, Tei J, Yamashita K, Onda M. A case of idiopathic esophageal rupture complicated with Mallory-Weiss syndrome. Gastroenterrol Endosc (Dig Endosc). 1988;30:730-3.

16. Nonomura O, Tanaka S, Ito T, Matsumura K, Takekoshi T, Sakai N, et al. A case report of Mallory-Weiss syndrome with the rupture of the esophagus. Jpn J Gastroenterol Surg. 1986;9:1807-11.

17. Cucci M, Caputo F, Orcioni GF, Roncallo A, Ventura F. Transition of a Mallory-Weiss syndrome to a Boerhaave syndrome confirmed by anamnestic, necroscopic, and autopsy data: a case report. Medicine (Baltimore). 2018;97:e13191.

18. Ito Y, Matsuoka N, Okita K, Igarashi Y, Kohama K, Sawano H, et al. Spontaneous esophageal rupture: review of 14 cases. Jpn J Acute Care Surg. 2018;8:173-8.

\section{Publisher's Note}

Springer Nature remains neutral with regard to jurisdictional claims in published maps and institutional affiliations.

Ready to submit your research? Choose BMC and benefit from:

- fast, convenient online submission

- thorough peer review by experienced researchers in your field

- rapid publication on acceptance

- support for research data, including large and complex data types

- gold Open Access which fosters wider collaboration and increased citations

- maximum visibility for your research: over $100 \mathrm{M}$ website views per year

At BMC, research is always in progress.

Learn more biomedcentral.com/submissions 